\title{
Wnt1 silencing enhances neurotoxicity induced by paraquat and maneb in SH-SY5Y cells
}

\author{
CUI HUANG ${ }^{1,2}$, JING MA $^{1}$, BAI-XIANG LI ${ }^{1 *}$ and YAN SUN ${ }^{1 *}$ \\ ${ }^{1}$ Department of Toxicology, School of Public Health, Harbin Medical University, Harbin, Heilongjiang 150081; \\ ${ }^{2}$ Safety and Quality Institute of Agricultural Products, Heilongjiang Academy of Agricultural Sciences, \\ Harbin, Heilongjiang 150086, P.R. China
}

Received July 30, 2018; Accepted July 23, 2019

DOI: $10.3892 /$ etm.2019.7963

\begin{abstract}
Wingless (Wnt) signaling regulates the proliferation and differentiation of midbrain dopamine (DA) neurons. Paraquat (PQ) and maneb (MB) are environmental pollutants that can be used to model Parkinson's disease (PD) in rodents. A previous study demonstrated that developmental exposure to PQ and MB affects the expression of Wnt1, Wnt5a, nuclear receptor-related factor 1 (NURR1) and tyrosine hydroxylase (TH). However, how Wnt signaling regulates these developmental factors in vitro is yet to be determined. To explore this, SH-SY5Y cells were exposed to PQ and MB. The results of the current study indicated that exposure to PQ and MB decreased Wnt1, $\beta$-catenin, NURR1 and TH levels and increased Wnt5a levels. Furthermore, Wntl silencing has the same effect as exposure to PQ and MB. Additionally, the neurotoxicity induced by PQ and MB is more severe in siWnt1-SH-SY5Y cells compared with normal SH-SY5Y cells. Therefore, Wnt1 may serve an important role in regulating developmental DA factors, and may be a candidate gene for PD diagnosis or gene therapy.
\end{abstract}

Correspondence to: Professor Bai-Xiang Li or Professor Yan Sun, Department of Toxicology, School of Public Health, Harbin Medical University, 157 Baojian Road, Nan Gang, Harbin, Heilongjiang 150081, P.R. China

E-mail: libaix@ems.hrbmu.edu.cn

E-mail: 13946167049@163.com

*Contributed equally

Abbreviations: PD, Parkinson's disease; DA, dopamine; PQ, paraquat; $\mathrm{MB}$, maneb; Wnt1, Wingless 1; Wnt5a, Wingless 5a; NURR1, nuclear receptor-related factor 1; TH, tyrosine hydroxylase; TBS, Tris-buffered saline; TBST, Tris-buffered saline with Tween; PBS, phosphate buffered saline; PBST, phosphate buffered saline with Tween; DAPI, 4',6-diamidino-2-phenylindole

Key words: Parkinson's disease, paraquat, maneb, wingless, SH-SY5Y

\section{Introduction}

Parkinson's disease (PD) is the second most common neurological disorder worldwide and is caused by the degeneration of midbrain dopamine (DA) neurons (1). The exposure to environmental toxins during development, which impact DA precursor factors, may lead to neurodegeneration and can increase the risk of developing PD $(2,3)$.

Wingless 1 (Wnt1) and Wingless 5a (Wnt5a), which are two members of the Wnt family, are developmental factors that regulate the proliferation and differentiation of DA precursors (4). Wnt1 enhances mesencephalic DA neuron differentiation (5), and Wnt5a can regulate midbrain DA axon growth and guidance (6). Additionally, Wnt1 and Wnt5a cooperate to regulate nuclear receptor-related factor 1 (NURR1) and tyrosine hydroxylase (TH) expression $(7,8)$. NURR1 is a brain-specific transcription factor located in DA neurons (9) and induces the neurogenesis of DA-phenotype neurons (10), while TH is a rate-limiting enzyme located in DA neurons and is associated with synthesizing DA (11). NURR1 can activate the promoter of $\mathrm{TH}$ gene in neural progenitor cells increasing TH expression $(12,13)$.

A previous study demonstrated that the developmental exposure to the herbicide paraquat (PQ) and the fungicide maneb (MB) in pregnant and lactating rats influenced the expression of Wnt1, Wnt5a, NURR1 and TH in the midbrain DA neurons of offspring (14). However, the mechanism of Wnt signaling in PD is still yet to be determined.

PQ and MB are two common agricultural chemicals, and their combined exposure has been used to model Parkinson-like motor deficits in rodents and to investigate the mechanisms of pathogenesis in this disease (15-18). However, the combined effect of $\mathrm{PQ}$ and $\mathrm{MB}$ in vitro, and their mechanism causing PD, is rarely reported. In the current study, the human SH-SY5Y neuroblastoma cell line, which is used as an in vitro cellular model of DA neurons, was exposed to PQ and MB to explore the mechanisms of Wnt signaling in PD.

\section{Materials and methods}

Chemicals, reagents and antibodies. PQ was purchased from J\&K Technology Co. Ltd. and MB was purchased from Sigma-Aldrich (Merck KGaA). Cell counting kit-8 (CCK-8) 
assay was purchased from TransGen Biotech Co., Ltd. Lipofectamine $2000^{\circledR}$ reagent was purchased from Invitrogen (Thermo Fisher Scientific, Inc.). Human Wnt1 gene small interfering RNA (siRNA; cat. no. sc-36839) was purchased from Santa Cruz Biotechnology, Inc.

Mouse monoclonal Wnt1 (cat. no. ab105740) and rabbit polyclonal Wnt5a (cat. no. ab174963) antibodies were purchased from Abcam. Rabbit polyclonal $\beta$-actin (cat. no. 20536-1-AP), rabbit polyclonal $\beta$-catenin (cat. no. 17565-1-AP), rabbit polyclonal NURR1 (cat. no. 10975-2-AP) and mouse monoclonal TH (cat. no. 6634-1-Ig) antibodies were purchased from Wuhan Sanying Biotechnology. Horseradish peroxidase (HRP)-labeled goat anti-rabbit (cat. no. ZB-2301) and goat anti-mouse (cat. no. ZB-2305) antibodies were purchased from Beijing Zhongshan Golden Bridge Biotechnology Co., Ltd. Alexa Fluor 647 labeled goat anti-rabbit (cat. no. ab150079), Alexa Fluor 488 labeled goat anti-mouse (cat. no. ab150113) and Alexa Fluor 488 labeled goat anti-rabbit (cat. no. ab150077) antibodies were purchased from Abcam.

Cell culture. SH-SY5Y cells were gifted from the School of Pathology in Harbin Medical University (Heilongjiang, China). Cells were cultured in high-glucose Dulbecco's Modified Eagle Medium containing 10\% FBS (Gibco; Thermo Fisher Scientific, Inc.) at $37^{\circ} \mathrm{C}$ in an incubator, under $5 \% \mathrm{CO}_{2}$ and $95 \%$ air. Cells were induced to differentiate through the administration of $10 \mu \mathrm{M}$ retinoic acid (Shanghai Aladdin Biochemical Technology Co., Ltd.) for 3-5 days in low serum medium, according to Kovalevich and Langford (19). Then, differentiated cells with a more pyramidal shaped body were used for the subsequent experiments.

CCK-8 assay. SH-SY5Y cells were seeded in 96-well plates and exposed to a range of doses of PQ, from $0-320 \mu \mathrm{M}$, and $\mathrm{MB}$, from $0-12.8 \mu \mathrm{M}$ for $24 \mathrm{~h}$. The culture medium was subsequently removed. Following the manufacturer's protocol, CCK-8 reagent was diluted in culture medium and added to wells. Each 96 -well plate was incubated at $37^{\circ} \mathrm{C}$ for $2 \mathrm{~h}$ prior to the detection of absorbance at $450 \mathrm{~nm}$. Inhibition rates were calculated according to the manufacturer's protocol.

Silencing Wnt1 in SH-SY5Y cells. A period of 1 day prior to transfection, cells were seeded in $75 \mathrm{~cm}^{2}$ culture bottles or 24-well plates in order to achieve $70 \%$ confluence for transfection. A specific siRNA (cat. no. sc-36839) for the human Wnt1 gene (GenBank accession no. NM_005430) was purchased from Santa Cruz Biotechnology, Inc. The human SH-SY5Y cell line was transfected using a Lipofectamine $2000^{\circledR}$ reagent according to the manufacturer's protocol. Cells in $75 \mathrm{~cm}^{2}$ culture bottles were transfected with $12.5 \mu 1$ of $10 \mu \mathrm{mol} / \mathrm{l} \mathrm{Wnt1}$ siRNA, while cells in 24-well plates were transfected with $4.5 \mu \mathrm{l}$ of $10 \mu \mathrm{mol} / 1 \mathrm{Wnt} 1 \mathrm{siRNA}$. A period of $4-6 \mathrm{~h}$ following transfection, the media was replaced with fresh growth media. Transfection efficiency was determined using western blot analysis.

Western blot analysis. Cells were collected and lysed in lysis buffer containing $1 \%$ protease inhibitor (both Beyotime Institute of Biotechnology) for $1 \mathrm{~h}$ at $4^{\circ} \mathrm{C}$. Samples were then centrifuged at $10,000 \mathrm{xg}$ at $4^{\circ} \mathrm{C}$ for $15 \mathrm{~min}$. Supernatants were

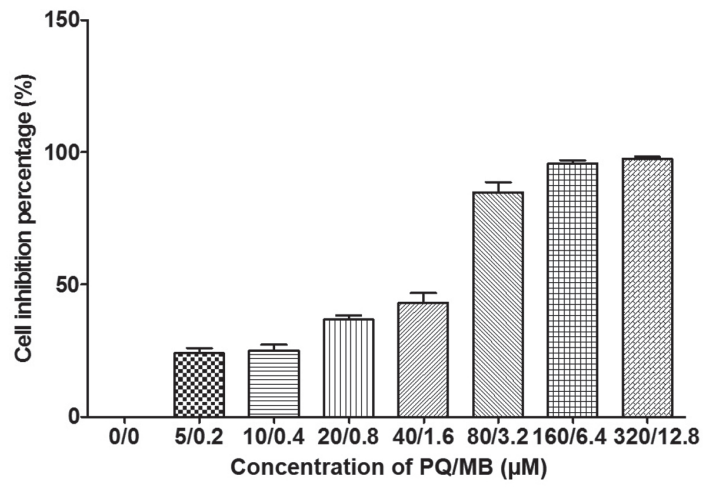

Figure 1. Inhibition by combined exposure to PQ and MB. SH-SY5Y cells in a 96-well plate were exposed to PQ and MB. The experiment was repeated three times. PQ, paraquat; MB, maneb.

collected and protein concentration was determined using a bicinchoninic acid protein assay kit (Beyotime Institute of Biotechnology). Equal amounts $(40 \mu \mathrm{g})$ of protein were separated by $10 \%$ SDS-PAGE and electrotransferred onto a PVDF (Merck KGaA). Membranes were blocked with 5\% non-fat milk for $1 \mathrm{~h}$ at room temperature prior to incubation overnight at $4^{\circ} \mathrm{C}$ in a solution of rabbit polyclonal $\beta$-actin $(1: 1,000)$, mouse monoclonal Wnt1 (1:500), rabbit polyclonal Wnt5a, rabbit polyclonal $\beta$-catenin, rabbit polyclonal NURR1 or mouse monoclonal TH (all 1:1,000). The next day, membranes were washed three times with tris buffered saline and incubated with HRP-labeled goat anti-rabbit and anti-mouse (both 1:5,000), Alexa Fluor 647-labeled goat anti-rabbit, and Alexa Fluor 488-labeled goat anti-rabbit and anti-mouse (all 1:1,000) secondary antibodies for $1 \mathrm{~h}$ at room temperature, and then washed three times with tris buffered solution with $0.5 \%$ tween. Targeted proteins were visualized using ECL reagent (Beyotime Institute of Biotechnology) and exposed to a film. Densities of specific protein bands were acquired using an Adobe Photoshop CS6 software (version 13.0; Adobe Systems Software Corporation). The results were expressed as the ratio of target protein to $\beta$-actin.

Immunofluorescence. Cell slides in the culture plate were washed with PBS three times. Cells were then fixed with $4 \%$ paraformaldehyde for $15 \mathrm{~min}$ at room temperature, and washed with PBS three times. Next, $0.5 \%$ Triton X-100 was used to permeabilize cell membranes for $20 \mathrm{~min}$ at room temperature. After washing slides three times with PBS, slides were dried with an absorbent paper. Non-specific antigens were blocked using ready-to-use goat serum (Beyotime Institute of Biotechnology) for $30 \mathrm{~min}$ at room temperature. Excess fluid was subsequently removed using absorbent paper. Mouse monoclonal Wnt1 (1:200), rabbit polyclonal Wnt5a, rabbit polyclonal $\beta$-catenin, rabbit polyclonal NURR1 or mouse monoclonal TH (all 1:500) primary antibodies were then dropped onto slides, which were then incubated in a wet box overnight at $4^{\circ} \mathrm{C}$. The next day, slides were washed three times with PBS containing $0.5 \%$ tween (PBST) and incubated with Alexa Fluor 488-labeled goat anti-mouse or anti-rabbit, or Alexa Fluor 647-labeled goat anti-rabbit or anti-mouse secondary antibodies (all 1:1,000) in a wet box for $1 \mathrm{~h}$ at room temperature. Slides were washed with PBST three times in 
A
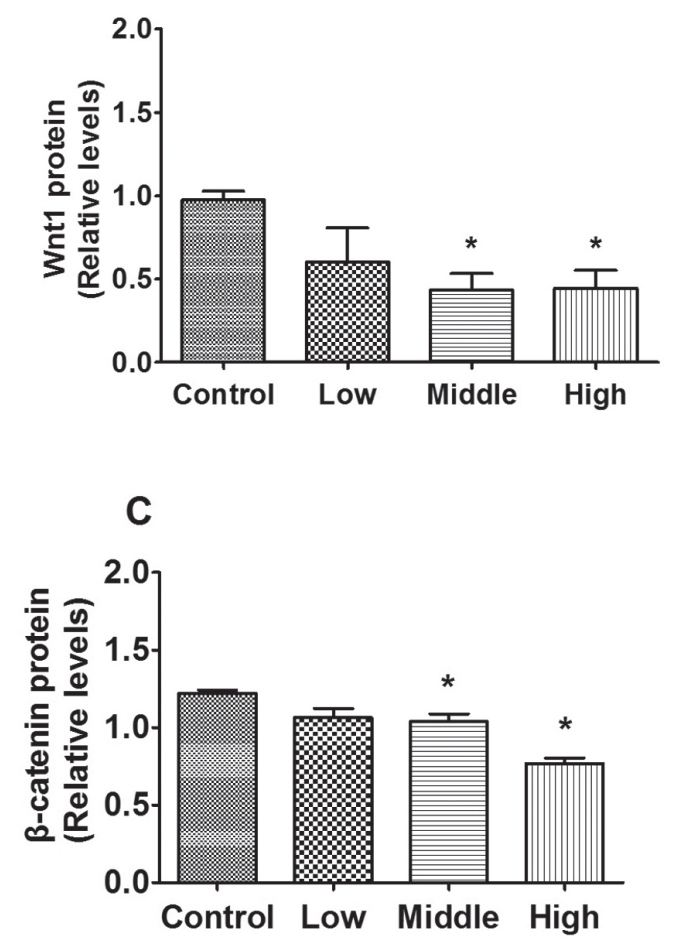

E

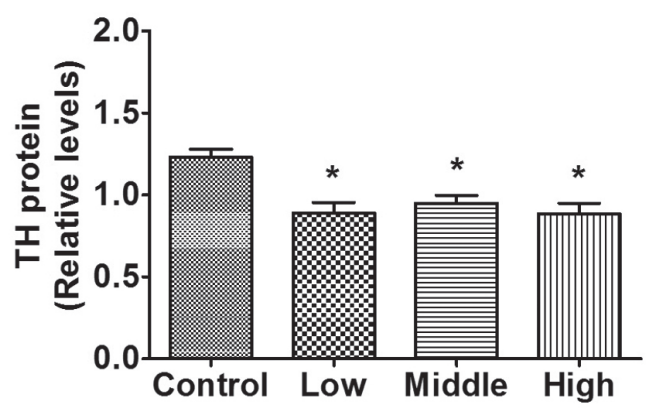

B
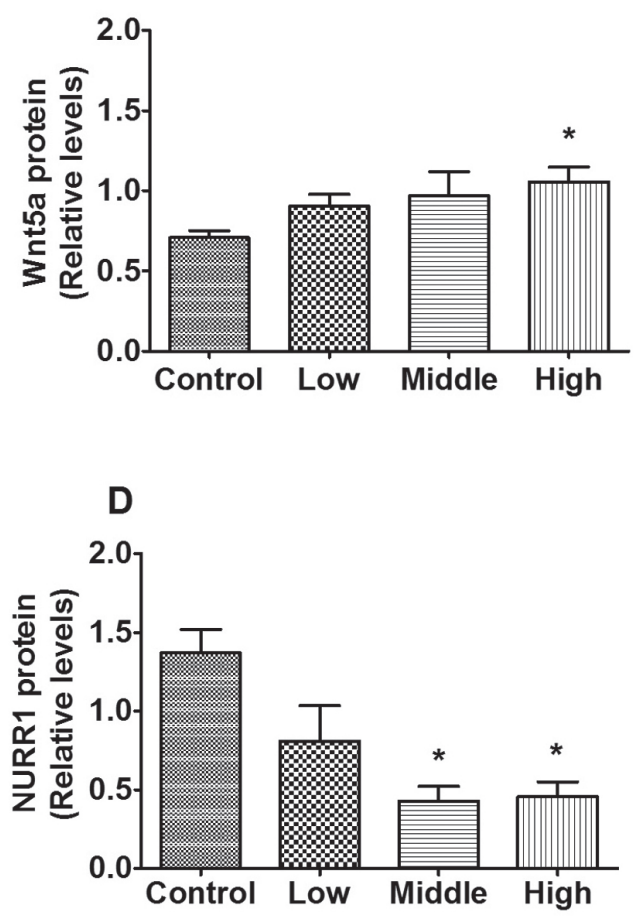

$\mathbf{F}$ Control Low Middle High

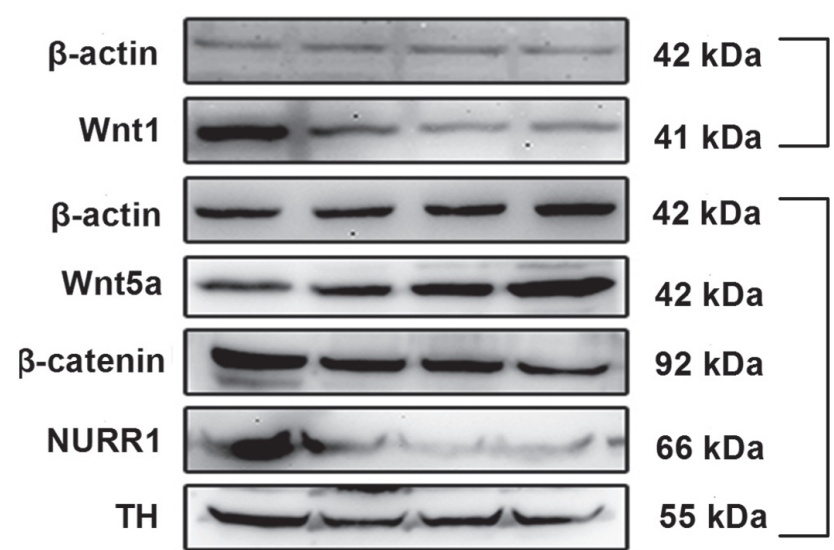

Figure 2. Effects of combined PQ/MB exposure on levels of Wnt pathway-associated proteins in SH-SY5Y cells. Protein expression of (A) Wnt1 (B) Wnt5a (C) $\beta$-catenin (D) NURR1 and (E) TH were analyzed using ANOVA followed Dunnett's T3 test. (F) Western blot analysis of Wnt1, Wnt5a, $\beta$-catenin, NURR1 and $\mathrm{TH}$ protein expression. $\mathrm{n}=3$. ${ }^{*} \mathrm{P}<0.05$ vs. control. PQ, paraquat; MB, maneb; Wnt1, wingless 1 ; Wnt5a, wingless 5a; NURR1, nuclear receptor-related factor 1 ; $\mathrm{TH}$, tyrosine hydroxylase.

the dark and then dried with an absorbent paper, and sealed with a sealing liquid containing anti-fluorescence quenching agent (Beyotime Institute of Biotechnology). Slides were then observed and images were collected using a Nikon Eclipse Ti fluorescence microscope (Nikon Corporation) with a magnification of $\times 200$.

Statistical analysis. All the data are presented as the mean \pm SEM and analyzed using SPSS 20.0 software (IBM Corp.). A one-way ANOVA was performed followed by a Dunnett's T3 test to analyze differences of Wnt pathway protein expression between the control and treatment groups following PQ and MB exposure (n=3). A two sample Student's t-test was used to analyze the differences of Wnt pathway protein expression between normal SH-SY5Y cells and Wnt1-silenced SH-SY5Y cells $(n=3) . P<0.05$ was considered to indicate a statistically significant difference.

\section{Results}

Inhibition of $S H-S Y 5 Y$ cell viability by $P Q-M B$ exposure. As presented in Fig. 1, average growth inhibition for $24 \mathrm{~h}$ in SH-SY5Y cells were $0,17,23,35,46,78,95$ and $97 \%$ at $\mathrm{PQ} / \mathrm{MB}$ doses of at 0/0, 5/0.2, 10/0.4, 20/0.8, 40/1.6, 80/3.2, $160 / 6.4$ and $320 / 12.8 \mu \mathrm{M}$, respectively.

Effects of combined exposure to $P Q$ and $M B$ on Wnt signaling. The first four doses of PQ and MB (saline, 


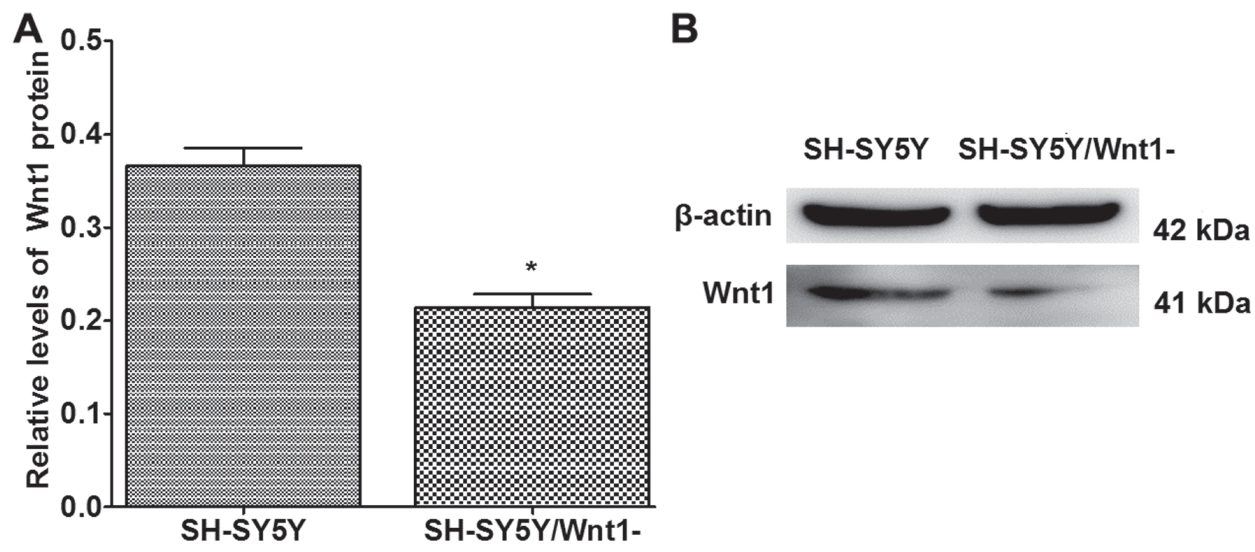

Figure 3. Silencing efficiency of Wnt1 in SH-SY5Y cells by siRNA. (A) Quantification of densitometry analysis in the control and silencing Wnt1 SH-SY5Y cells. (B) Western blot analysis of Wnt1 protein expression in the control and silencing Wnt1 SH-SY5Y cells. n=3. "P<0.05. Wnt1, wingless 1; siRNA, small interfering RNA.

A

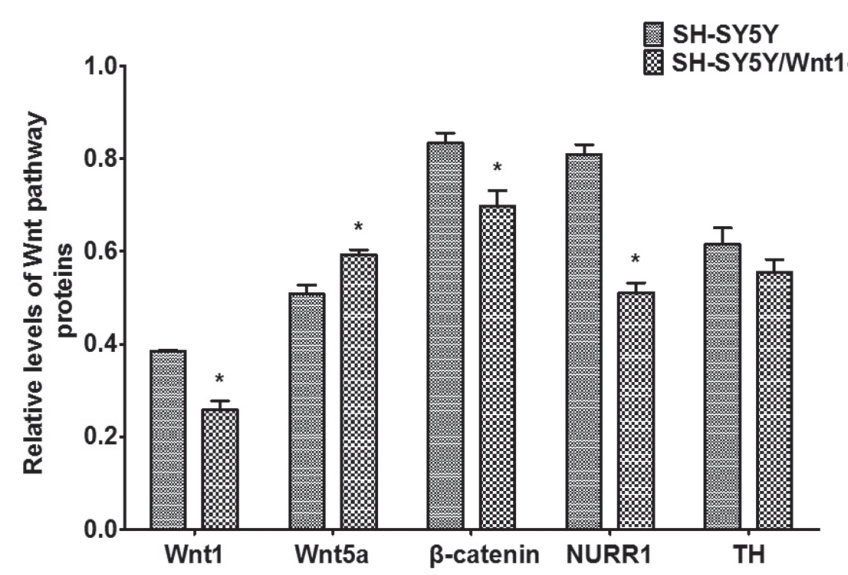

B

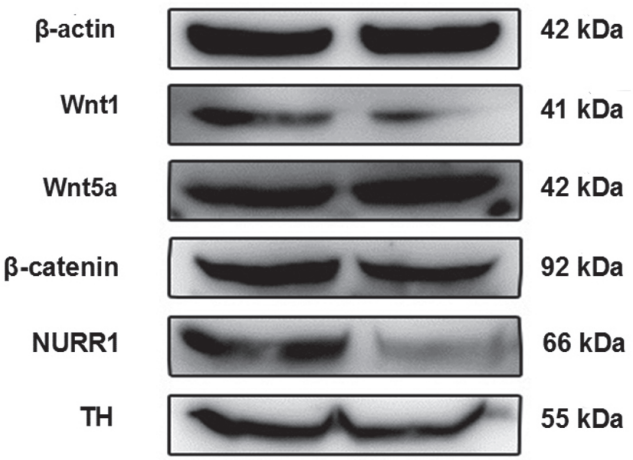

Figure 4. Expression levels of proteins following Wnt1 silencing. (A) Quantification of densitometry analysis following Wnt1 silencing in SH-SY5Y cells. (B) Western blot analysis of protein following Wnt1 silencing in SH-SY5Y cells. Protein expression in SH-SY5Y cells and SH-SY5Y/Wnt1-cells were analyzed using a two sample Student's t-test. $\mathrm{n}=3$. ${ }^{*} \mathrm{P}<0.05$. Wnt1, wingless 1; Wnt5a, wingless 5a; NURR1, nuclear receptor-related factor 1; TH, tyrosine hydroxylase.

5/0.2, 10/0.4 and 20/0.8 $\mu \mathrm{M}$ ) were used as control, low, middle and high dosages of exposure for SH-SY5Y cells as the inhibitions were $<50 \%$. Western blot analysis was used to measure the effects of protein expression that was associated with Wnt signaling.

As indicated in Fig. 2A, compared with the control, Wnt1 protein expression significantly decreased in the middleand high-dose groups $(\mathrm{P}=0.013$ and $\mathrm{P}=0.019$, respectively). Additionally, $\beta$-catenin and NURR1 expression in the middle- $(\mathrm{P}=0.044$ and $\mathrm{P}=0.001$, respectively; Fig. $2 \mathrm{C}$ and $\mathrm{D})$ and high-dose groups $(\mathrm{P}=0.007$ and $\mathrm{P}=0.007$, Fig. $2 \mathrm{C}$ and $\mathrm{D}$, respectively) were significantly decreased compared with the control group, and TH expression in the low, middle and high dose groups were significantly decreased compared with the control group $(\mathrm{P}=0.010, \mathrm{P}=0.009$ and $\mathrm{P}=0.009$, respectively; Fig. 2E). Wnt5a protein levels were significantly increased in the high-dose group compared with the control group ( $\mathrm{P}=0.047$; Fig. 2B).

Silencing efficiency of Wnt1. Human-specific Wnt1 siRNA was used to silence Wnt1 expression in SH-SY5Y cells. The silencing efficiency of Wnt1 in SH-SY5Y cells was $~ 50 \%$, and the difference was significant when compared with normal SH-SY5Y cells $(\mathrm{P}<0.001$; Fig. 3$)$.

Effects of Wnt1 silencing on dopaminergic factors. The expression of proteins that are associated with Wnt signaling were investigated following Wnt1 silencing in SH-SY5Y cells. As presented in Fig. 4, Wnt1, $\beta$-catenin and NURR1 protein levels were significantly decreased $(\mathrm{P}=0.164, \mathrm{P}=0.024$ and $\mathrm{P}=0.001$, respectively), whereas the level of Wnt5a protein significantly increased $(\mathrm{P}=0.022)$. TH expression also decreased, although the difference was not significant. These changes were similar to the effects of PQ- and MB-induced toxicity on protein levels indicated in a previous in vivo study (14).

Wnt1 silencing enhances toxicity induced by combined exposure to $P Q$ and MB. Normal SH-SY5Y and Wnt1-silencing SH-SY5Y cells were exposed to PQ and MB (at doses of 20 and $0.8 \mu \mathrm{M}$, respectively). Immunofluorescence was used to visualize Wnt1, Wnt5a, $\beta$-catenin, NURR1 and TH proteins. As shown in Fig. 5, the fluorescence of Wnt1, $\beta$-catenin, NURR1 and TH proteins 


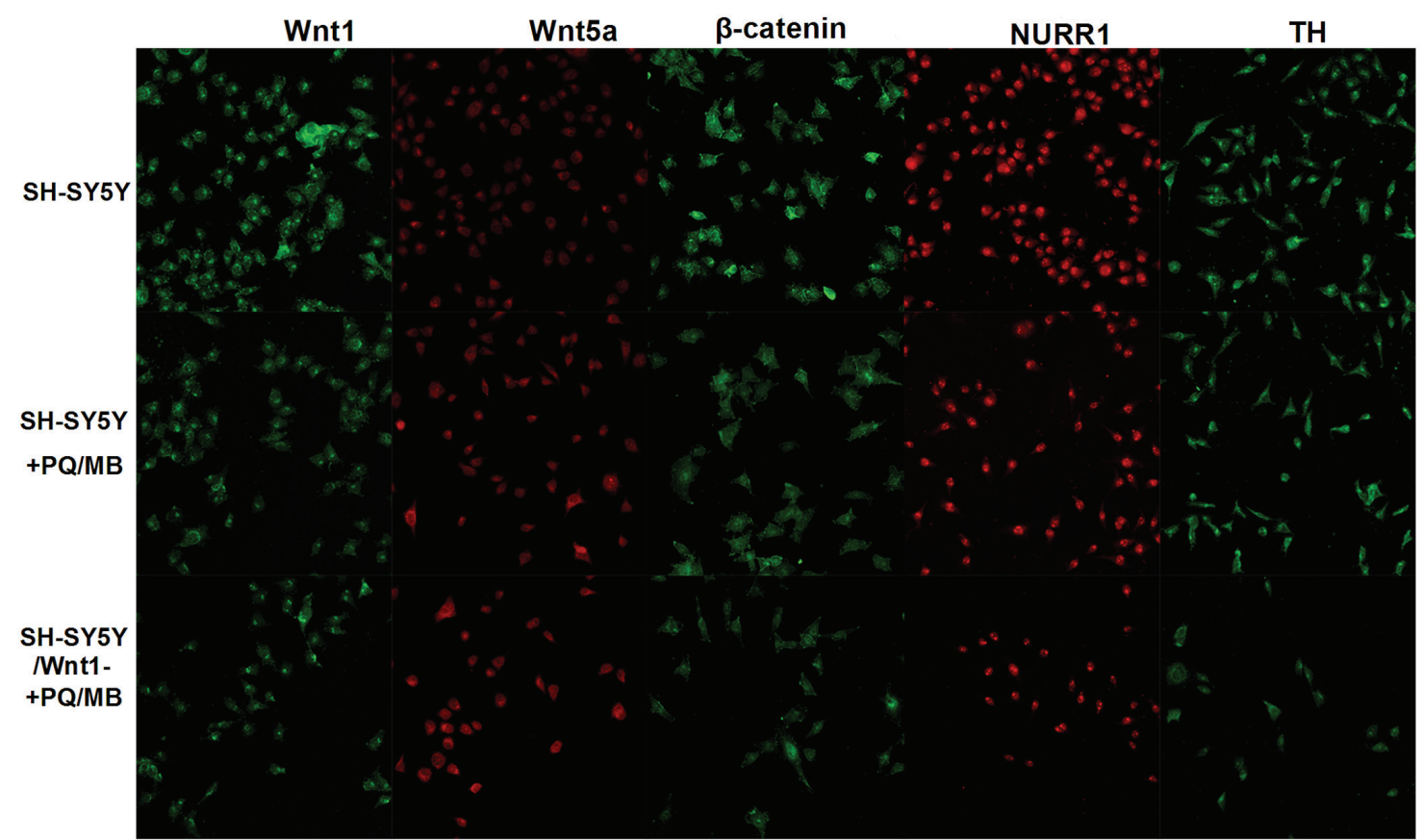

Figure 5. Effects on down-stream Wnt pathway proteins in normal SH-SY5Y and Wnt1 silenced SH-SY5Y cells following exposure to the same doses of PQ and MB (20 and $0.8 \mu \mathrm{M})$. PQ, paraquat; MB, maneb; Wnt1, wingless 1; Wnt5a, wingless 5a; NURR1, nuclear receptor-related factor 1; TH, tyrosine hydroxylase.

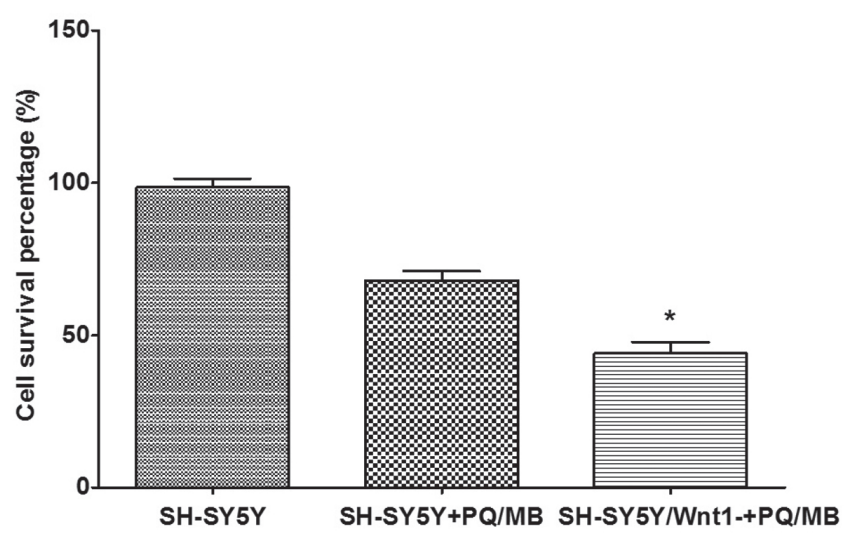

Figure 6. Silencing Wnt1 expression enhances PQ and MB-induced toxicity in SH-SY5Y cells. The cell survival percentage in Wnt1 silenced SH-SY5Y cells was lower compared with normal SH-SY5Y cells following exposure to the same doses of $\mathrm{PQ}$ and $\mathrm{MB}(20$ and $0.8 \mu \mathrm{M})$. Data are presented as the mean \pm SEM. $n=5$. ${ }^{*} \mathrm{P}<0.05$. PQ, paraquat; $\mathrm{MB}$, maneb; Wnt1, wingless 1.

weakened in SH-SY5Y and SH-SY5Y/Wnt1-cells treated with PQ and MB compared with untreated SH-SY5Y cells, whereas the fluorescence of Wnt5a intensified.

Cytotoxicity was performed using a CCK- 8 assay. The results presented in Fig. 6 indicated that the cell survival percentage in Wnt1-silencing cells decreased more than normal SH-SY5Y cells after exposure to the same doses of $\mathrm{PQ}$ and $\mathrm{MB}$, which indicated that cell damage was more severe. The differences were significant in the Wntl silenced and the $\mathrm{PQ} / \mathrm{MB}$ treatment groups when compared with the control group $(\mathrm{P}<0.001)$.

Collectively, the hypothesized relationship between Wnt1, Wnt5a, $\beta$-catenin, NURR1 and TH is summarized in Fig. 7. Wnt1 plays a positive role on down-stream genes, $\beta$-catenin, NURR1 and TH, Wnt5a plays a negative role. There is also an interaction between Wnt1 and Wnt5a.

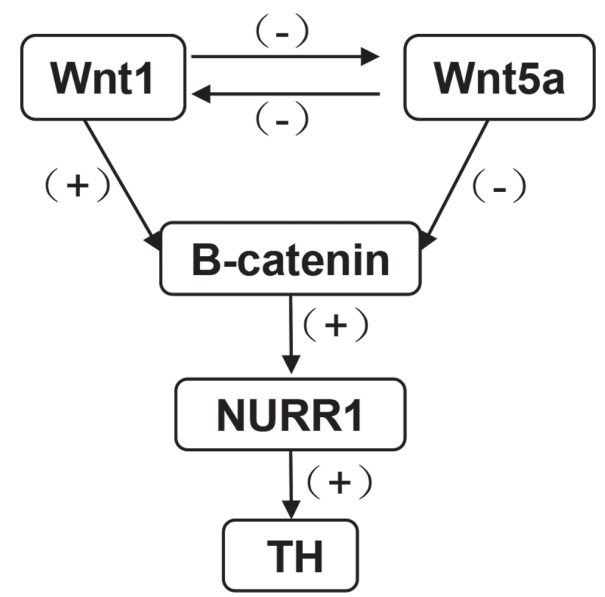

Figure 7. Diagram presenting the interactions between Wnt1, Wnt5a, $\beta$-catenin, NURR1 and TH following exposure to PQ and MB. Wnt1 has a positive regulation on down-stream genes, $\beta$-catenin, NURR1 and TH, and a negative regulation on Wnt5a. Wnt1, wingless 1; Wnt5a, wingless 5a; NURR1, nuclear receptor-related factor $1 ; \mathrm{TH}$, tyrosine hydroxylase; PQ, paraquat; $\mathrm{MB}$, maneb; +, positive regulation; -, negative regulation.

\section{Discussion}

The SH-SY5Y cell line is frequently used as an in vitro cellular model of DA neurons in neurotoxicity research (20-23). However, according to Kovalevich and Langford (19), the SH-SY5Y cell line exhibits three morphologically distinct phenotypes during development: A spindle shaped cell body, pyramidal shaped body and epithetial-like cell body. The pyramidal shaped cell exhibits increased neuronal functions. Therefore, spindle shaped cells were induced to differentiate into pyramidal cells in a method that was reported by Kovalevich and Langford (19). The PQ and MB 
dose used in the current study was selected based on previous reports $(24,25)$. Inhibition in SH-SY5Y cells was acquired for $24 \mathrm{~h}$ under exposure to PQ and MB. Doses with inhibition rates of $0,17,23$, and $35 \%$ were used as the control, low-, middle-, and high-exposure groups, respectively.

In the current in vitro study, $\mathrm{PQ}$ and MB-induced toxicity in SH-SY5Y cells decreased Wnt1, NURR1 and TH expression, and increased Wnt5a expression. These results are consistent with results from a previous in vivo study (14). Additionally, the in vitro expression of $\beta$-catenin was investigated in the current study. $\beta$-Catenin is part of the canonical Wnt pathway, which is essential for the neurogenesis of midbrain DA neurons (26-28). Mice with a targeted deletion of $\beta$-catenin have been demonstrated to exhibit deficits in motor learning and memory (29). The results of the current study indicated that exposure to PQ and MB reduces $\beta$-catenin and Wnt1 expression levels in SH-SY5Y cells. This reduction may also influence the survival rate of SH-SY5Y cells.

$\beta$-Catenin has also been demonstrated to protect PC12 cells against rotenone-induced neurotoxicity through the induction of NURR1 expression (30). NURR1 is a transcription factor that regulates the development of DA precursors into mature DA neurons (31). In NURR1-deficient mice, DA dysfunction occurs during ageing (32-34). Therefore, NURR1 is considered to be a PD candidate gene (35). TH, which is a DA neuronal marker expressed in mature DA neurons, has been indicated to be regulated by NURR1 (36). In the current study, NURR1, TH, Wnt1 and $\beta$-catenin were all decreased after exposure to PQ and MB.

Wnt5a serves a role in the development of midbrain DA neurons (37). However, in contrast to Wnt1, $\beta$-Catenin, NURR1 and TH protein levels, Wnt5a protein levels did not decrease in toxic SH-SY5Y cells induced by PQ and MB, and conversely increased Wnt5a in the current study and a previously reported in vivo study (14). This increased Wnt5a may be a compensatory response to the induction of NURR1 and TH expression. A previous study has also indicated that Wnt5a can inhibit the canonical Wnt pathway and promote cardiac progenitor development (38). Therefore, it can be suggested that increased Wnt5a may also inhibit Wnt1 expression, but this needs to be investigated.

In developing DA neurons, Wnt1 is expressed on embryonic day 8 (E8) (39), prior to the expression of Wnt5a on E9.5 (40), $\beta$-catenin on E9.5 (41), NURR1 on E10.5 (42) and TH on E11.5 (43). To explore the effect of Wnt1 on $\beta$-catenin, Wnt5a, NURR1 and TH, Wnt expression was silenced in SH-SY5Y cells. The results were similar to those of toxicity induced by PQ and MB, which indicated that $\beta$-catenin, NURR1, and TH were decreased while Wnt5a was increased. Therefore, the results of the current study demonstrated that Wnt1 expression serves an important role in maintaining DA neuron function.

After exposure of normal SH-SY5Y cells and Wnt1-silenced SH-SY5Y cells to $20 \mu \mathrm{M}$ PQ and $0.8 \mu \mathrm{M}$ MB, a decreased cell survival was observed in Wnt1-silencing cells compared with normal SH-SY5Y cells. The results of the present study demonstrated that Wntl silencing enhances the neurotoxicity that is induced by PQ and MB. This finding is similar to that of a previous study, which reported that exogenous Wntl protects SH-SY5Y cells against 6-hydroxydopamine toxicity (44). In conclusion, the results of the current study revealed that Wnt1 may be an effective candidate gene for the treatment of PD, but this needs to be investigated further.

\section{Acknowledgements}

Not applicable.

\section{Funding}

The current study was supported by a grant from the National Natural Science Foundation of China (grant no. 81402711).

\section{Availability of data and materials}

All data generated or analyzed during this study are included in this published article.

\section{Authors' contributions}

BXL and YS designed the study. $\mathrm{CH}$ performed the experiments and wrote the manuscript. JM analyzed the data. All authors read and approved the final manuscript.

\section{Ethics approval and consent to participate}

The present study was approved by Harbin Medical University (Heilongjiang, China).

\section{Patient consent for publication}

Not applicable.

\section{Competing interests}

The authors declare that they have no competing interests.

\section{References}

1. Calabrese V, Santoro A, Monti D, Crupi R, Di Paola R, Latteri S, Cuzzocrea S, Zappia M, Giordano J, Calabrese EJ and Franceschi C: Aging and Parkinson's Disease: Inflammaging, neuroinflammation and biological remodeling as key factors in pathogenesis. Free Radic Biol Med 115: 80-91, 2018.

2. Feng P, Zhang X, Li D, Ji C, Yuan Z, Wang R, Xue G, Li G and Hölscher C: Two novel dual GLP-1/GIP receptor agonists are neuroprotective in the MPTP mouse model of Parkinson's disease. Neuropharmacology 133: 385-394, 2018

3. Chinta SJ, Woods G, Demaria M, Rane A, Zou Y, McQuade A, Rajagopalan S, Limbad C, Madden DT, Campisi J and Andersen JK: Cellular senescence is induced by the environmental neurotoxin paraquat and contributes to neuropathology linked to Parkinson's disease. Cell Rep 22: 930-940, 2018.

4. Castelo-Branco G, Wagner J, Rodriguez FJ, Kele J, Sousa K, Rawal N, Pasolli HA, Fuchs E, Kitajewski J and Arenas E: Differential regulation of midbrain dopaminergic neuron development by Wnt-1, Wnt-3a, and Wnt-5a. Proc Natl Acad Sci USA 100: 12747-12752, 2003.

5. De Gregorio R, Pulcrano S, De Sanctis C, Volpicelli F, Guatteo E, von Oerthel L, Latagliata EC, Esposito R, Piscitelli RM, Perrone-Capano C, et al: $\mathrm{miR}-34 \mathrm{~b} / \mathrm{c}$ regulates Wnt 1 and enhances mesencephalic dopaminergic neuron differentiation. Stem Cell Reports 10: 1237-1250, 2018.

6. Blakely BD, Bye CR, Fernando CV, Horne MK, Macheda ML, Stacker SA, Arenas E and Parish CL: Wnt5a regulates midbrain dopaminergic axon growth and guidance. PLoS One 6: e18373, 2011. 
7. Kitagawa H, Ray W, Glantschnig H, Nantermet P, Yu Y, Leu CS, Kato S and Freedman L: A regulatory circuit mediating convergence between Nurr1 transcriptional regulation and Wnt signaling. Mol Cell Biol 34: 917, 2014.

8. Andersson ER, Saltó C, Villaescusa JC, Cajanek L, Yang S, Bryjova L, Nagy II, Vainio SJ, Ramirez C, Bryja V and Arenas E: Wnt5a cooperates with canonical Wnts to generate midbrain dopaminergic neurons in vivo and in stem cells. Proc Natl Acad Sci USA 110: E602-E610, 2013.

9. Li HY, Liu F and Wang HR: Correlation between Nurr1 expression and drug resistance in the brain of rats with epilepsy. Eur Rev Med Pharmacol Sci 22: 1506-1513, 2018.

10. Chen XX, Qian Y, Wang XP, Tang ZW, Xu JT, Lin H, Yang ZY, Song XB, Lu D, Guo JZ, et al: Nurr1 promotes neurogenesis of dopaminergic neuron and represses inflammatory factors in the transwell coculture system of neural stem cells and microglia. CNS Neurosci Ther 24: 790-800, 2018.

11. Nagatsu T and Nagatsu I: Tyrosine hydroxylase (TH), its cofactor tetrahydrobiopterin (BH4), other catecholamine-related enzymes, and their human genes in relation to the drug and gene therapies of Parkinson's disease (PD): Historical overview and future prospects. J Neural Transm 123: 1255-1278, 2016.

12. Kim KS, Kim CH, Hwang DY, Seo H, Chung S, Hong SJ, Lim JK, Anderson T and Isacson O: Orphan nuclear receptor Nurr1 directly transactivates the promoter activity of the tyrosine hydroxylase gene in a cell-specific manner. J Neurochem 85: 622-634, 2010.

13. Ding Y, Zhang Z, Ma J, Xia H, Wang Y, Liu Y, Ma Q, Sun T and Liu J: Directed differentiation of postnatal hippocampal neural stem cells generates nuclear receptor related-1 protein- and tyrosine hydroxylase-expressing cells. Mol Med Rep 14: 1993-1999, 2016.

14. Ma J, Huang C, Ma K, Wu YP, Li BX and Sun Y: Effect of Wnt1 and Wnt5a on the development of dopaminergic neurons, and toxicity induced by combined exposure to paraquat and maneb during gestation and lactation. Mol Med Rep 16: 9721-9728, 2017.

15. Tinakoua A, Bouabid S, Faggiani E, De Deurwaerdere P, Lakhdar-Ghazal N and Benazzouz A: The impact of combined administration of paraquat and maneb on motor and non-motor functions in the rat. Neuroscience 311: 118-129, 2015.

16. Bastias-Candia S, Di Benedetto M, D'Addario C, Candeletti S and Romualdi P: Combined exposure to agriculture pesticides, paraquat and maneb, induces alterations in the N/OFQ-NOPr and PDYN/KOPr systems in rats: Relevance to sporadic Parkinson's disease. Environ Toxicol 30: 656-663, 2015.

17. Desplats P,Patel P,Kosberg K, Mante M,Patrick C,Rockenstein E, Fujita M, Hashimoto M and Masliah E: Combined exposure to maneb and paraquat alters transcriptional regulation of neurogenesis-related genes in mice models of Parkinson's disease. Mol Neurodegener 7: 49, 2012.

18. Gupta SP, Patel S, Yadav S, Singh AK, Singh S and Singh MP: Involvement of nitric oxide in maneb- and paraquat-induced Parkinson's disease phenotype in mouse: Is there any link with lipid peroxidation? Neurochem Res 35: 1206-1213, 2010.

19. Kovalevich J and Langford D: Considerations for the use of SH-SY5Y neuroblastoma cells in neurobiology. Methods Mol Biol 1078: 9-21, 2013

20. $\mathrm{Xu}$ T, Niu $C$, Zhang $X$ and Dong M: $\beta$-Ecdysterone protects SH-SY5Y cells against $\beta$-amyloid-induced apoptosis via c-Jun $\mathrm{N}$-terminal kinase- and Akt-associated complementary pathways. Lab Invest 98: 489-499, 2018

21. Song Y, Liu Y and Chen X: MiR-212 attenuates MPP ${ }^{+}$-induced neuronal damage by targeting KLF4 in SH-SY5Y cells. Yonsei Med J 59: 416-424, 2018

22. Wang CY, Sun ZN, Wang MX and Zhang C: SIRT1 mediates salidroside-elicited protective effects against $\mathrm{MPP}^{+}$-induced apoptosis and oxidative stress in SH-SY5Y cells: Involvement in suppressing MAPK pathways. Cell Biol Int 42: 84, 2018.

23. Presgraves SP, Borwege S, Millan MJ and Joyce JN Involvement of dopamine $\mathrm{D}(2) / \mathrm{D}(3)$ receptors and BDNF in the neuroprotective effects of S32504 and pramipexole agains 1-methyl-4-phenylpyridinium in terminally differentiated SH-SY5Y cells. Exp Neurol 190: 157-170, 2004.

24. Roede JR, Hansen JM, Go YM and Jones DP: Maneb and paraquatmediated neurotoxicity: Involvement of peroxiredoxin/thioredoxin system. Toxicol Sci 121: 368-375, 2011.

25. Caputi FF, Carretta D, Lattanzio F, Palmisano M, Candeletti S and Romualdi P: Proteasome subunit and opioid receptor gene expression down-regulation induced by paraquat and maneb in human neuroblastoma SH-SY5Y cells. Environ Toxicol Pharmacol 40: 895-900, 2015.
26. Tang MZ and Huang EJ: $\beta$-Catenin controls neurogenesis of midbrain dopamine neurons through cell adhesion and junctional complex formation. Int J Dev Neurosci 26: 886-886, 2008.

27. Colini Baldeschi A, Pittaluga E, Andreola F, Rossi S, Cozzolino M, Nicotera G, Sferrazza G, Pierimarchi P and Serafino A: Atrial natriuretic peptide acts as a neuroprotective agent in in vitro models of Parkinson's disease via Up-regulation of the Wnt/ß-catenin pathway. Front Aging Neurosci 10: 20 , 2018.

28. Davis SW, Mortensen AH, Keisler JL, Zacharias AL, Gage PJ, Yamamura $\mathrm{K}$ and Campe SA: $\beta$-catenin is required in the neural crest and mesencephalon for pituitary gland organogenesis. BMC Dev Biol 16: 16, 2016.

29. Diaz-Ruiz O, Zhang Y, Shan L, Malik N, Hoffman AF, Ladenheim B, Cadet JL, Lupica CR, Tagliaferro A, Brusco A and Bäckman CM: Attenuated response to methamphetamine sensitization and deficits in motor learning and memory after selective deletion of $\beta$-catenin in dopamine neurons. Learn Mem 19: 341-350, 2012

30. Zhang L, Luan C, Qu S, Lei W, Mo M, Feng J, Sun C, Xiao Y, Qin L, Li S, et al: Enhancing beta-catenin activity via GSK3beta inhibition protects PC12 cells against rotenone toxicity through Nurrl induction. PLoS One 11: e0152931, 2016.

31. Smits SM, Ponnio T, Conneely OM, Burbach JP and Smidt MP: Involvement of Nurrl in specifying the neurotransmitter identity of ventral midbrain dopaminergic neurons. Eur J Neurosci 18 : 1731-1738, 2003

32. Ahn JH, Lee JS, Cho JH, Park JH, Lee TK, Song M, Kim H, Kang SH, Won $\mathrm{MH}$ and Lee $\mathrm{CH}$ : Age-dependent decrease of Nurr1 protein expression in the gerbil hippocampus. Biomed Rep 8: 517-522, 2018.

33. Dong J, Wang Y, Liu XY and Le WD: Nurr1 deficiency-mediated inflammatory injury to nigral dopamine neurons in Parkinson's disease. Parkinsonism Relat Disord 46: e66, 2018.

34. Kummari E, Guo-Ross S and Eells JB: Region specific effects of aging and the Nurr1-Null heterozygous genotype on dopamine neurotransmission. Neurochem Neuropharmacol 3: pii: 114, 2017.

35. Le W, Pan T, Huang M, Xu P, Xie W, Zhu W, Zhang X, Deng H and Jankovic J: Decreased NURR1 gene expression in patients with Parkinson's disease. J Neurol Sci 273: 29-33, 2008.

36. Sakurada K, Ohshima-Sakurada M, Palmer TD and Gage FH: Nurr1, an orphan nuclear receptor, is a transcriptional activator of endogenous tyrosine hydroxylase in neural progenitor cells derived from the adult brain. Development 126: 4017-4026, 1999

37. Parish CL, Castelo-Branco G, Rawal N, Tonnesen J, Sorensen AT, Salto C, Kokaia M, Lindvall O and Arenas E: Wnt5a-treated midbrain neural stem cells improve dopamine cell replacement therapy in parkinsonian mice. J Clin Invest 118: 149-160, 2008.

38. Bisson JA, Mills B, Paul Helt JC, Zwaka TP and Cohen ED Wnt5a and Wnt11 inhibit the canonical Wnt pathway and promote cardiac progenitor development via the Caspase-dependent degradation of AKT. Dev Biol 398: 80-96, 2015.

39. Panhuysen M, Vogt Weisenhorn DM, Blanquet V, Brodski C, Heinzmann U, Beisker W and Wurst W: Effects of Wnt1 signaling on proliferation in the developing mid-/hindbrain region. Mol Cell Neurosci 26: 101-111, 2004.

40. Andersson ER, Prakash N, Cajanek L, Minina E, Bryja V, Bryjova L, Yamaguchi TP, Hall AC, Wurst W and Arenas E: Wnt5a regulates ventral midbrain morphogenesis and the development of A9-A10 dopaminergic cells in vivo. PLoS One 3: e3517, 2008.

41. Joksimovic $M$ and Awatramani R: Wnt/ $\beta$-catenin signaling in midbrain dopaminergic neuron specification and neurogenesis. J Mol Cell Biol 6: 27-33, 2014.

42. Prakash N and Wurst W: Development of dopaminergic neurons in the mammalian brain. Cell Mol Life Sci 63: 187-206, 2006.

43. Alves dos Santos MT and Smidt MP: En1 and Wnt signaling in midbrain dopaminergic neuronal development. Neural Dev 6: 23, 2011.

44. Wei L, Sun C, Lei M, Li G, Yi L, Luo F, Li Y, Ding L, Liu Z, $\mathrm{Li} \mathrm{S}$ and $\mathrm{Xu}$ P: Activation of Wnt/ $\beta$-catenin pathway by exogenous Wnt1 Protects SH-SY5Y cells against 6-hydroxydopamine toxicity. J Mol Neurosci 49: 105-115, 2013. 